\title{
FOREIGN AID, SUSTAINABLE DEVELOPMENT AND RAPTI IRDP
}

Madhusudan Sharma Subedi

\begin{abstract}
Perhaps it would be appropriate to refer to 'aid' as 'involvement' of the more developed countries in the economic, political, military and social sectors of developing countries, either directly or through international agencies.
\end{abstract}

- Katar Singh 1999:310

\section{Introduction}

The issue of foreign aid and sustainable development, as it usually applies to the developing countries, is full of the apparent dilemmas and contradictions. There are many roots for these contradictions. The first one is the discrepant interest of sets of actors involved in the aid game. Aid operated projects have appeal to the affluent donors as well as development countries' politicians and decision makers. Projects come into existence and get implemented in a fascinating process. Often they precipitate from multistage processes of which we can identify at least three: agenda setting, planning and implementation. At each stage of these processes there are alternative courses of action, with more open options and relatively more power at the top. There are many variables involved in the equation.

The main concern of this paper is to deal with the role of foreign aid in Nepal's development. In the mid nineties, I got an 
opportunity to travel different parts of the Rapti Zone. There I observed two faces: children without clothes, farmers without food, traditional occupational groups without job, and a few well equipped local elites enjoying all locally available facilities. I remembered the Rapti IRDP, a mega project funded by USAID, which was just completed. I talk with local farmers who were far from roadhead, with dalits who were going to kala pahar, India for seasonal labour, and I also talked with local elites, contractors who were saying about Rapti project and its benefit to them. I also observed the real life situation of people living is differents of the Rapti Zone. Here, I shall present some realities of Rapti Integrated Rural Development Project (Rapti-IRDP) from the political economy perspective.

\section{Foreign Aid and Sustainable Development: Cross Cutting Issues}

Foreign aid in its generic sense is defined as a flow of capital from the developed to less developed or developing countries. It is given at a concessional term and with a view, when it is purely economic, development and general welfare of the people in the recipient countries. Aid generally serves three objectives: political, economic and humanitarian. These three objectives are not separable but are rather mutually interdependent. Whatever objectives a donor agency (country) would like to achieve, the general belief is that aid promotes development in the receiving countries.

The term 'sustainable development' has been used differently by different scholars. Many development workers and donor agencies' reports become incomplete without this word. What are we trying to sustain? This is a very crucial issue for the social scientists, and especially for the sociologist and anthropologists for the developing countries like Nepal where the plans and policies are directly influenced by external forces and donor agencies. It is also important to note that the conditions and dynamics of the sustainable development vary among different types of activities.

World Commission on Environment and Development, popularly known as Brundtland Commission defines sustainable development as, "development that meets the needs of the present without compromising the ability of the future generation to meet their own needs (WCED 1987 quoted in Goldman 2000:293)". In this sense sustainable development is a process that can be maintained without interruption, weakening or loss of valued qualities for future generations. This concept sustainable development leaves scope for dynamic adjustments in institutional factors (such as market, community and state), economic factors (such as investment) and scientific and technological factors, and above all, encompasses both needs and aspirations (Chopra and Kadekodi 1999). However, there are unlimited needs for the present generation itself. How can we think for the future generation without fulfilling basic needs and other requirements for the present generation? Brown et al. (1987:717), on the other hand, write, "In the narrowest sense, global sustainability means the indefinite survival of the human species across all the regions of the world..... The broadest sense of global sustainability includes the persistence of all components of the biosphere, even those with apparent benefit to humanity". In this definition, it is very difficult to make an indicator to evaluate an empirically based approach to sustainability of development activities. What is or are object(s) of sustainability? How do we know whether something is or is not sustainable, or is more or less sustainable than something else? What are the main threats to and sources of sustainability for the things we want to sustain?

My argument here is that we should take development as a vector of desirable social objectives which should include: increase in real income per capita; improvement in health and nutritional status; 
educational achievement; access to resources; a fairer distribution of income; increases in basic freedoms. The sustainable development is a situation in which the development vector does not decrease over time. Thus the concept of sustainable development encompasses: help for the very poor, marginalized and disadvantaged; self-reliant development; basic health and education facilities for all; clean water and shelter for all; human beings, in other words, are the resources in this concept. We should focus not only economic growth but overall development of human beings. Sustainable development must be ecologically sound, economically viable, socially just, and culturally appropriate. Are we getting positive indications by using huge amount of foreign aid in the name of development or the development aid has created dualism? What are the main threats and source of sustainability? This is an issue to evaluate the use and misuse of foreign in the name of development.

Thus, relationship between foreign aid and sustainable development has been one of the most controversial issues in aid literature. There has been big concern both in donor and recipient countries about the effectiveness of foreign aid. By the mid-sixties, evaluation of the impact of aid also became one of the important issues in developing countries. Case studies of some countries had already warned that aid had failed to attain its goals (Dhungana 1981; Hardin 1977; Haaland 1990; Khadka 1991; Mishra and Sharma 1983; Pandey 1983; Poudyal 1982). These studies, however, work as a basis for more rigorous and detailed examination of this issue. Not only are the results inconclusive, but also that these results polarized between the supporters and the opponents of aid. At least, three different views can be mentioned.

One view is represented by the conservatives who consider aid as unnecessary. This group poses the question why the poor people of the industrialized countries should be taxed to support the richer people in the poor countries. This group thinks that aid is supporting the repressive regimes and urban elites. Another view is represented by the radicals who consider aid as "imperialism". This group thinks that aid is used as an instrument to perpetuate the exploitation of the poor countries. The school of dependency falls into this category. According to this group, the assistance that developing countries receive with so many conditions in terms of material import requirement and expatriate in such a way that the net flow remains very low. Of the total aid provided a large proportion is siphoned off by the donors by trying technology and manpower imports of their own origin, which would mean that the net amount available to be actually spent inside the country is far less than what is recorded. Of this net amount some proportion is apportioned for financing the study or observation visit of highranking officials from the donor countries. Thus, a large proportion of assistance does not enter into directly productive activities, and whatever proportion is finally used that too suffers from ineffective utilization (Poudyal 1982). It has been empirically found that the net investment out of the gross foreign assistance comes to only about 25 percent. About 10 percent of the total project's cost goes in terms of wages and this is the only benefit that the majority of the poor receive actually (Dhungana 1981). Haaland (1990:1), for example, writes "Aid projects attempting to break this vicious circle has to confront a multifaceted problem involving not only technoeconomic and socio-cultural conditions, but also fundamental ethical dilemmas. It is easy to say that one must take poverty and environmental degradation into consideration in planning development projects, it is notoriously difficult to design a practical course of action which promotes economic growth and at the same time leads to a distributions of benefits which reach the poor without having the effects which undermine the ecological basis for viable 
adaptation." He further writes "if the development agencies are serious about their task they have to ask questions about the will and the ability of particular government to engage in different phases of development activities from planning, to implementation and maintenance. These questions have to be placed in the political context of different ethnic groups and their ability to influence the government's economic policy, as well as in the contexts of administrative culture influencing the performance of bureaucratic personnel (ibid.:17).

In Nepal, almost all of the foreign aided projects are either directly located in the urban centers or in the close vicinity of such centers. The ultimate result is that the beneficiaries are urban elite and urban well-to-do contractors. The poor and the downtrodden are basically left out for all practical purpose. It leads us to greater dependency. By virtue of foreign aid the rich have been gotten richer while the position of the poor has worsened. One commonality between these two views is that both the radicals and the conservatives have cast a slur upon aid and argue for immediate withdrawal. In between these two arguments lies the pragmatist group. This group believes in the dynamic role of aid and advocates for more aid in order to create the possibilities of development in recipient countries. Some variants for this group recommends for using aid effectiveness as the critical parameter for allocating countries requiring aid.

Theoretically, the contribution of foreign aid in recipient economy will be, (a) to release resource constraints caused either by insufficiency of domestic saving or lack of adequate foreign exchange, and (b) to overcome the technical constraints posed by the lack of technical know-how and skill. The particular role of aid will be applied in the case of countries that have adequate resources but insufficient technological base. The former will be applied in the case of countries, which, over a period of time, have created the technological bases but lack the adequate financial resources for its efficient use.

The rapid development in the science and technology has posed ethical questions to the utilities and values of each of the development concepts in different interval of time and place. Eventually in some cases, they contributed to improve the quality of our lives. But, at the same time, science and technology have equally heightened a sense of risk, which seems to threaten the natural balance of our life support system. How can we evolve human and ecological ethics to economic mores so the sphere of social institutions adequately provides the scope for a new social contract between nature and culture, between rich and poor, and between male and females? Such ethical issues are vital to the idea of striking an interface between ecological sustainability, economic efficiency and sustainable livelihood of the people. The key question confronting us today is: How to achieve a sense of balance where the positive features of each of these mediating agents serve human security? (Hering 1997 n.d.)

\section{Theoretical Debates on Aid and Sustainability}

Although sustainability as a concept and value has been widely advocated, and numerous definitions have been given, there is no consensus on the meaning of the term. The main proponents of the concept are probably those who view sustainability in terms of stewardship and preservation of resources and ecosystems with maintenance of sustained yield capacity of resources as primary objectives. It is usually defined as the social and economic change that meets the needs and aspirations of this generation without jeopardizing the ability of future generation to do the same. The intellectual heritage of this school derives mainly from ecological theory and from the tradition of sustained yield resource use and extraction. The social norms often associated with this theme 
educational achievement; access to resources; a fairer distribution of income; increases in basic freedoms. The sustainable development is a situation in which the development vector does not decrease over time. Thus the concept of sustainable development encompasses: help for the very poor, marginalized and disadvantaged; self-reliant development; basic health and education facilities for all; clean water and shelter for all; human beings, in other words, are the resources in this concept. We should focus not only economic growth but overall development of human beings. Sustainable development must be ecologically sound, economically viable, socially just, and culturally appropriate. Are we getting positive indications by using huge amount of foreign aid in the name of development or the development aid has created dualism? What are the main threats and source of sustainability? This is an issue to evaluate the use and misuse of foreign in the name of development.

Thus, relationship between foreign aid and sustainable development has been one of the most controversial issues in aid literature. There has been big concern both in donor and recipient countries about the effectiveness of foreign aid. By the mid-sixties, evaluation of the impact of aid also became one of the important issues in developing countries. Case studies of some countries had already warned that aid had failed to attain its goals (Dhungana 1981; Hardin 1977; Haaland 1990; Khadka 1991; Mishra and Sharma 1983; Pandey 1983; Poudyal 1982). These studies, however, work as a basis for more rigorous and detailed examination of this issue. Not only are the results inconclusive, but also that these results polarized between the supporters and the opponents of aid. At least, three different views can be mentioned.

One view is represented by the conservatives who consider aid as unnecessary. This group poses the question why the poor people of the industrialized countries should be taxed to support the richer people in the poor countries. This group thinks that aid is supporting the repressive regimes and urban elites. Another view is represented by the radicals who consider aid as "imperialism". This group thinks that aid is used as an instrument to perpetuate the exploitation of the poor countries. The school of dependency falls into this category. According to this group, the assistance that developing countries receive with so many conditions in terms of material import requirement and expatriate in such a way that the net flow remains very low. Of the total aid provided a large proportion is siphoned off by the donors by trying technology and manpower imports of their own origin, which would mean that the net amount available to be actually spent inside the country is far less than what is recorded. Of this net amount some proportion is apportioned for financing the study or observation visit of highranking officials from the donor countries. Thus, a large proportion of assistance does not enter into directly productive activities, and whatever proportion is finally used that too suffers from ineffective utilization (Poudyal 1982). It has been empirically found that the net investment out of the gross foreign assistance comes to only about 25 percent. About 10 percent of the total project's cost goes in terms of wages and this is the only benefit that the majority of the poor receive actually (Dhungana 1981). Haaland (1990:1), for example, writes "Aid projects attempting to break this vicious circle has to confront a multifaceted problem involving not only technoeconomic and socio-cultural conditions, but also fundamental ethical dilemmas. It is easy to say that one must take poverty and environmental degradation into consideration in planning development projects, it is notoriously difficult to design a practical course of action which promotes economic growth and the same time leads to a distributions of benefits which reach the poor without having the effects which undermine the ecological basis for viable 
adaptation." He further writes "if the development agencies are serious about their task they have to ask questions about the will and the ability of particular government to engage in different phases of development activities from planning, to implementation and maintenance. These questions have to be placed in the political context of different ethnic groups and their ability to influence the government's economic policy, as well as in the contexts of administrative culture influencing the performance of bureaucratic personnel (ibid.:17).

In Nepal, almost all of the foreign aided projects are either directly located in the urban centers or in the close vicinity of such centers. The ultimate result is that the beneficiaries are urban elite and urban well-to-do contractors. The poor and the downtrodden are basically left out for all practical purpose. It leads us to greater dependency. By virtue of foreign aid the rich have been gotten richer while the position of the poor has worsened. One commonality between these two views is that both the radicals and the conservatives have cast a slur upon aid and argue for immediate withdrawal. In between these two arguments lies the pragmatist group. This group believes in the dynamic role of aid and advocates for more aid in order to create the possibilities of development in recipient countries. Some variants for this group recommends for using aid effectiveness as the critical parameter for allocating countries requiring aid.

Theoretically, the contribution of foreign aid in recipient economy will be, (a) to release resource constraints caused either by insufficiency of domestic saving or lack of adequate foreign exchange, and (b) to overcome the technical constraints posed by the lack of technical know-how and skill. The particular role of aid will be applied in the case of countries that have adequate resources but insufficient technological base. The former will be applied in the case of countries, which, over a period of time, have created the technological bases but lack the adequate financial resources for its efficient use.

The rapid development in the science and technology has posed ethical questions to the utilities and values of each of the development concepts in different interval of time and place. Eventually in some cases, they contributed to improve the quality of our lives. But, at the same time, science and technology have equally heightened a sense of risk, which seems to threaten the natural balance of our life support system. How can we evolve human and ecological ethics to economic mores so the sphere of social institutions adequately provides the scope for a new social contract between nature and culture, between rich and poor, and between male and females? Such ethical issues are vital to the idea of striking an interface between ecological sustainability, economic efficiency and sustainable livelihood of the people. The key question confronting us today is: How to achieve a sense of balance where the positive features of each of these mediating agents serve human security? (Hering 1997 n.d.)

\section{Theoretical Debates on Aid and Sustainability}

Although sustainability as a concept and value has been widely advocated, and numerous definitions have been given, there is no consensus on the meaning of the term. The main proponents of the concept are probably those who view sustainability in terms of stewardship and preservation of resources and ecosystems with maintenance of sustained yield capacity of resources as primary objectives. It is usually defined as the social and economic change that meets the needs and aspirations of this generation without jeopardizing the ability of future generation to do the same. The intellectual heritage of this school derives mainly from ecological theory and from the tradition of sustained yield resource use and extraction. The social norms often associated with this theme 
involve preservation of resource potential for future generations. Since much of the conceptual and analytic grounding derives from experience in extraction of renewable resources, there is strong concern with rates of extraction in relation to rates of natural and human managed regeneration. The notion of carrying capacity, borrowed from ecological studies of nonhuman populations and applied to human systems, plays a large integrative role. As a result, population growth and/or the growth of economic demand are often seen as the principal sources of threat to agricultural sustainability. Even in the absence of direct population pressure on land, excess use of modern inputs, including agrochemicals, energy, and in some cases irrigation, is also seen as a major threat to sustainability, either through negative environmental impact or resource depletion (Goldman 1995: 292-295). There are problems with making this definition workable because hard decisions need to be made about what is to be sustained. It is not possible to maximize everything at once, including biological, social, and economic goals and values.

Secondly, the mainstream economists argue that resource concerns must be tempered with the consideration of economic needs and desires. There is greater focus on meeting economic needs. The third strand is linked to the sociological tradition and emphasizes maintenance of community as well as of social values such as equity and quality of life. It suggests that neither resources nor economic welfare are sufficient objects of sustainability if the human community and its social values are not also maintained. Political economists have also addressed sustainable development, often by combining elements of three things. They argue for the necessity of understanding historical process, class relations, and the structures of the international economic system in analyzing the obstacles to sustainable resource use and development.

\section{Foreign Aid, Poverty and Stagnation in Nepal: An Overview}

Due to the multiple dimensional effects of aid on the economy, it is difficult to identify certain comprehensive indicators of performance of aid. It is even more difficult in the case of the country like Nepal, which has no systematic database and has only a limited national base accounting system. Both donors and recipients have different purpose of, and approach to, evaluation of the impact of aid on the economy.

Nepal started its developmental activities in a planned manner in 1956 and ever since the process of planning and development is continuing. The basic planning objectives have been to target expenditure for various sectors of economy such as agriculture, industry and transportation in each development plan. These financial outlays call for increase in production and gross domestic product without considering the environment degradation, which results from the development projects. The total investment pattern and financing of it over the period of more than four decades shows that foreign aid financed more than fifty per cent of the total resources. There are some visible sign of progress during the past fifty years. A roadless country in 1950, Nepal has built many paved highways, new branded jeeps are imported, communication facilities are improved, and literacy rate has increased and many more buildings are made. This would not have been possible without foreign aid. At the same time, there are many visible scars of environmental degradation, the results of roads, dams and bridges carelessly constructed without environmental safeguards. The need for short-term economic returns led them to dismiss or give low priority to any potential environmental hazards in development projects. There are frequent famines, and the process of erosion and ecological decline, coupled with continuing population growth (Blaikie, Cameron and Seddon 1980). The large-scale exploitation of ecosystem for strictly economic ends has produced 
disastrous results-ecosystem have been degraded and economic benefits have turned out to be illusory (Karan and Iijima 1986:282). A collection of Nepalese scholars, in an October 1983 seminar termed by a World Bank official as a "landmark events" of public cognizance, concluded that aid programs have completely missed their ultimate mark. "Agriculture has not benefited; the poor have been bypassed; the women have not even been understood; the relations of production and distribution of power have gotten worse and the technical assistance has not contributed to the improvement of administrative capability", the participants wrote in their final statement (Pandey 1983: 282). The worst news is, the population continues to explode, erosion continues to eat away topsoil, and cooking fires continue to consume forest cover without arrest; virtually all arable land in the country has now been colonized (Luhan 1987:29). Mishra and Sharma (1983) argued that in the context of the country like Nepal, "development through foreign aid essentially becomes a metaphor for the maintenance and strengthening of the traditional native power structure. They further argued that the upper social classes were driving the major benefits from foreign aided development. Foreign aid, therefore, enhances the position of the upper social classes who benefit from the maintenance of the existing system of political and economic power. Mishra and Sharma further argued that the foreign aided development projects has had no significant effect on mode of production but role of foreign aid has consisted in the increase of political dependence of the underclass.

This simple issue illustrated "how our country is experiencing its so called magic of development, decentralization, economic upliftment, and local self governance all amount to just bureaucratic jargons. They are adornments employed by ghost speechwriters for ministries. They are jargons that turn people at the grassroots into parrots for they do not know what these actually mean (Adhikari 2000:92)."

According to Nepal Human Development Report 1998, poverty in Nepal has increased at an annual rate of 3 percent and the number of absolute poor has nearly doubled in the last two decades. Similarly, while the share of bottom 40 percent of population in total income was 23 percent in 1985 , it declined to 11 percent in 1996, and the share of top 10 percent has increased from 23 percent to 52 percent (NESAC 1998:116). In 1977, the proportion of households falling below the poverty line was estimated at 33.7 percent, it increased to 42.6 percent in 1985 , and 45 percent in 1996, an increase of nearly 9 percent points within two decades (NESAC 1998:126-27). Disparity in distribution of both assets and income, in turn, influences access to education, health, nutrition and standard of living. Inequality in household land holding also remains pronounced. Rural-urban inequality, which is large and growing, remains another salient feature (Mishra 2000). Consumption expenditures show that the poor households spend two-thirds of their total income on basic food items, and can spend only a tiny amount to fulfill other needs-those related to clothing, education, health, shelter, utilities etc (Mishra 2000). In terms of global ranking, Nepal ranked 144 among the 174 countries (UNDP 1999). How this situation evolved, which long time development hands have watched with growing dismay and regret, has to do with both the logic of foreign aid and Nepal's domestic culture. But the core of the problem has been completely disjoined planning to justify the inflow of aid, coupled with donors' blind urge to continue pushing projects rather than coherent policies.

The attitude of foreign aid is greatly affected by the Nepali sense of paternal dependency. For example, a prominent anthropologist of Nepal writes - "foreign aid donors are sometimes seen as father- 
surrogates. ... When this passive paternal dependency is applied to foreign aid, the only active agent of development becomes the foreign party, who then must supply the resources, the administration, the imagination to plan, and the motivation to make it all work (Bista 1991:136)".

Thus, rural development efforts in Nepal have had little success in achieving their objectives. The regular changes in rural development strategy have certainly helped bring more and more foreign aid into the country. Much less has been accomplished regarding the social mobilization and economic development of those who suffer from absolute poverty and intolerable social and political suppression (Devkota 1992).

It would, however, be wrong to judge the performance of economy in terms of foreign aid only. But as foreign aid does provide substantial help to overcome the financial constraint, which generally constitute the major development constraint, the pace of country's development should have been somewhat better than what it is. Though foreign aid has contributed to the establishment of some roads, communication systems, irrigation, power, drinking water large industries and higher education have all been benefited by foreign assistance. In fact there is hardly any development project totally financed by domestic resources. It is true that had there been be no foreign aid, the country would not have developed these projects for many years, but the question is whether these projects represents all that we could have done from the inflow of foreign capital (Poudyal 1982).

Similarly, foreign advisors gain more personal and professional benefits from the projects than Nepali counterparts. In 1978, for example, for a foreign staff member or advisor in Nepal, was getting a million rupees per year other facilities whereas a Nepal for the similar type of work Nepali officer was getting between 20,000 to 30,000 rupees per (Justice 1986). She further writes, "Although foreigners live in various parts of Kathmandu, they tend to cluster in certain areas where enterprising Nepalese have built new houses with western style amenities and plumbing, specifically for the purpose of renting to foreigners. These houses are well equipped and spacious by most western standards, many being located in large gardens surrounded by trees and greenery. Some organizations, such as USAID and the Canadian International Development Agency, furnish them with imported appliances and Western-style furniture made by local craftsmen. Allowances are provided for domestic servants - cooks, bearers, watchman, gardeners, and ayahs (nannies). Utilities are often maintained and paid for by the donor organization (Justice 1986:39)". Observing this situation, Stiller and Yadav (1979:58) have rightly said, "foreign aid is good business for Kathmandu, it is equally profitable for foreigner advisors, many of whom live at a social economic level above what they could expect in their home country." Thus in addition to humanitarian and professional motives, financial motives cannot be overlooked as a reason for accepting foreign consultancies (Justice 1986). This situation has raised the questions of about the actual flow of budget to the target groups and cost-benefit analysis of the project.

For better or worse, donor aid and Nepalese development will be inextricably linked in foreseeable future. Nepal government has virtually ceded all development authority to the donors. Almost major projects reveal a predictable pattern: foreign design, funded and implemented from beginning to end. The Rapti Integrated Rural Development Project (Rapti-IRDP), funded by U.S. Agency for International Development (USAID), provides an example.

\section{Rural Development Project in Rapti Zone (Rapti-IRDP)}

After the overthrow of Rana Regime, USA and India made breakthrough in $1951 / 52$ by providing the first quantum of 
assistance to Nepal in the form of grants. Consequently, the first Five Year Plan was launched in 1956 totally financed by foreign aids (Poudyal 1982). When we review year-to-year aid flow, it is an increasing trend. The concept of IRDP was adopted in the Fifth Five Year Plan (1975-1980). Principally, IRDP "aims at providing income-generating assets and self-employment opportunities to the rural poor, to enable them to rise above the poverty line once and for all. IRDP in effect, seeks to redistribute assets and employment opportunities in favor of the rural poor, and thereby reduce income inequality (Singh 1999:224)". The goal of implementing the IRDP in Nepal was to provide an effective development strategy characterized by participatory planning and decentralized development administration.

The first phase of Rapti-IRDP was launched in 1980 according to the Base Line Survey done in 1979 by a government research organ, APROSC, to generate a brief "project identification document". It was the biggest IRDP in terms of area coverage and financial involvement. A lot of study and preparation had gone into the formulation of the project (Pradhan 1982:28). In the design of the project it had been recognized that the five years of proposed activity must be part of a longer 15-20 years intense development effort. Donors were arguing that several subsequent effort, with donor support, were likely to be required to respond to and sustain local development initiatives, integration, functional specialization, economic stabilization and growth within the Rapti Zone (Pradhan 1982:28). In 1987, HMG Nepal and the USAID signed the project grant agreement to launch the second phase activity for the development of the Rapti Zone. In 1991, The Rapti Development Project (RDP) directed its attention to increasing household income and well-being through increased productivity and sustainable management of farm and forest resource systems.
When we view geographically, Dang district lies entirely in the inner tarai region. The three districts of Rolpa, Pyuthan and Salyan and major parts of Rukum district lie in the mid-hill region. A small part of the Rukum district in the north-east and north-west lie in the high altitude Himalayan region. AID brought dozens of Washington experts into the zone to expand its development possibilities. AID then signed a five-year agreement with the Nepalese government to finance "Rapti I" an ambitious IRDP, and contracted with PADCO, a Washington-based firm, to act as the technical assistance manager. The main objectives of the projects were to:

1. Increase production and consumption of food by the people of Rapti Zone;

2. Construct new roads and maintenance of the old roads; and

3. Strengthen the capacity of Panchayats (now called Village development committee) and other local organizations to plan, implement and sustain local development efforts.

The theme of Rapti - IRDP was poverty alleviation but the development process led to frustration as the poverty increased despite two decades of development efforts. An interim evaluation, according to an AID official, found that cereal production in the region - targeted for a $27 \%$ expansion - had increase "minimally, perhaps $5 \%$ at most" (Luhan1987: 31). The grain production has increased in the zone mainly from increased area cultivated and notably in the hill districts. Rapid population growth and the low production records in the agriculture sector have also direct socioeconomic implication for nutritional deficiency and reduced per capita food consumption in the hill and mountain villages in Rolpa, Salyan and Rukum districts, this has created other vicious problems. For example, decline in production forced the population of the two regions to take recourse to two measures: (a) encroach upon new forest for acquiring new land for cultivation, and (b) drift 
into the terai and urban areas in search for jobs. Since the extension of land through encroaching upon the forest is limited, the interregional migration from the hill districts to the Dang valley has been increasing very fast. This means that land ratio in the hill and mountains crossed the minimum support limit of agricultural sector. The man-land ratio is now declining in the terai also.

Another dimension of the problem is the growing environmental degradation. The new or marginal land for cultivation has devastating effect on the forest resources. The continuous encroachment upon forest depleted this resource and hence pushed the environment to a critical level. The ecological balance between natural environment and population growth has been disrupted to a larger extent. This could be directly related to soil erosion and drought caused from time to time. As in many parts of the country, more than $90 \%$ of the required fuel energy is met through forest resources, the increasing drain on the forest resources is the main factor responsible for the environmental degradation. As a consequence of this, landslides, floods and silt-laden rivers have become common problem. The consequence of ecological imbalance caused by population growth also affected the downstream. Deforestation in the hill districts caused to the siltation and floods in the plain.

One of the critical implications of foreign aid investment in agriculture sector is its failure to link up agricultural development with socio-economic and infrastructure sectors. The government failed to make genuine efforts to generate economic possibilities for investment in agricultural sector. For example, the investment in road transport sector had no linkage effects either on agricultural production or on its marketing. The program of Rapti IRDP was to upgrade and improve three roads in zonal level of about $288 \mathrm{~km}$. existing trails. These roads linked the administrative headquarters of Salyan, Rolpa and Pyuthan districts with the Zonal centers of
Tulsipur and Ghorahi. We do not have information about the economic viability of the roads. The economic viability of these roads was not systematically investigated before the roads were economically justified for construction. On the contrary, the people were deprived of the local products as part of the produce had been diverted towards the urban area. The small farmers and poor peasants did not gain much because, first of all, there was an intrusion by the big traders and merchants who monopolized the market through bullish and bearish trading practices and secondly, they lack both financial leverage and market information on price of agricultural commodities. Thus, the construction of road took away the local production by the powerful merchants and traders to the cities. A few producers profited because of the market, but majority of the population in the rural areas suffered because they had to pay higher prices for the same produce. Another implication of foreign aid vis-à-vis performance of agricultural sector is that it did not contribute to the development of projects on an institutional basis. As the projects / programs earmarked in the budget are determined by the political consideration, each member in the parliament tried to get some projects in his / her constituency in order to win over the voters. These projects/programs were (and still are funded by other donor agencies) politically motivated and economically short lived. They were not guided by the consideration of specificity in terms of exact nature of program, its scope and continuity and complementarily. For instance, some expenditure were allocated for building irrigation, piped water supply and gully protection projects in a particular area which had an immediate impact to create an impression on the local people. Since no accurate evaluation studies were done, there were no information and records whether or not those projects are running or disappeared. Many of the projects selected by the vested interest groups suffered because of lack of provision for the supply of inputs, maintenance cost, administrative 
and institutional arrangements for the operation of projects. Lack of sound institutional arrangement for the provisional complementarily supplies, in fact, favored the big farmers.

One of the serious effects of the road is the creation of socieconomic and technical dualism between "on-the-road areas" and "off-the-road areas". Opening of roads have caused out migration from the "off-the-road" to the "on-the-road areas" or from the rural to urban areas. Another effect of road networks is technological dualism. Though there is no big revolution in using the technology in the urban areas on the roadsides, but in terms of facilities provided with the opening of the roads made those two areas different. People living along the roadsides can get cheaper fertilizer vis-à-vis the improved varieties of seeds and pesticides but people living in the rural areas have to depend on traditional methods of cultivation. All these caused inequalities to widen, in both income and space between these two areas.

The need for road network and the cost of repair and maintenance should also be examined in terms of social equity. If one looks at the type of automobiles and their ownership pattern, it is clear that the beneficiaries of the roads are the richer community. Most of the vehicles are privately owned. The charges the owner of the vehicles pay is very insignificant compared to the benefit they receive. Considering the repair and maintenance costs, it will not be justified to subsidize roads for the use of few richer people in any country. From social equity point of view also, roads have not yielded significant benefit to the poor people. Even during the construction phase the real benefits of the road projects was very limited due to the use of capital-intensive techniques.

Capital intensive technology destroyed the livelihoods of laborers, and commercialization those of artisans. Both concentrate wealth in the hands of those already less poor, and enable them to become wealthier, to buy more land, to appropriate more of a larger surplus, and to expand their trade. These processes also weakened traditions of mutual responsibility and sharing between patrons and clients, and between the small farmers and landless. Social relationship with obligation gave way to cash relationships without obligation (Chambers 1983).

Despite the huge investment in irrigation, the evaluation team reported that the performance of the medium irrigation components of the Rapti IRDP was disappointing, not only due to contracting and administrative delays, but also due to the implementing agency's inability or unwillingness to include social factor in project design or to illicit beneficiary participation (Bista 2000:92). The major irrigation projects were concentrated in the plain areas and the hill areas did not show any sign of improvement. This investment was not being linked with other agricultural inputs such as, credits, fertilizers, marketing channels, and technical services. The use and supply of water were also politically determined. Since the local government was involved in the operation of the projects, the advantages were reaped by the powerful landlords because these are the people who control the local political and economic affairs. The selection of projects itself were done on the political consideration and hence the use is inevitably political.

In the sector where the aid investment was direct because of capital intensive nature and high degree of technological requirements, the achievements made were more visible, at least in quantitative terms. The positive change in the quantitative magnitude of some of these are, if examined without analyzing, (a) the cost-benefits, (b) the cost-effectiveness, (c) problem of local cost and maintenance, and (d) socio-economic inequalities, buildings made by the project for different service centers look impressive. These are sectors where aid-investments have comparatively directly observable and 
pronounced achievements. The voluminous increase in aid investment large on buildings constructions should be measured by the actual use and not by the amount of investment or the size of its quantity. The dalits and marginalized ethnic groups, small farmers, landless labors, workers and urban poor who comprise 90 percent or our population, and it is them under whose name development plans and programs are designed and yet they are the ones least cared about.

Though consultancy firms had been invariably used in developing Rapti project, donor seemed to dominate in the processes of project formulation. It made not only unrealistic assumptions but also distortions. In the formulation of the project, the existing institutional arrangements had been ignored, though the 'users committee' was often mentioned. Neglect of this important resource, on the one hand, and the raising of expectations that foreign resources are coming in a big way to develop the area, on the other hand, had brought about an erosion of self-help attitude and developed 'aid mentality' among the people. The influence is worst in project headquarters and service centers. It decreases as we move away from these centers.

As a matter of fact the complete dependency on foreign aid- a cheap money (as considered by many people) - further corrupted the thinking, values and attitudes of our people who are working as a higher administrative or a professional/consultant. The tendency that somebody else's money has come, had led to wastage and misappropriations (Dhungana 1981). It was also observed that there was a tendency for leakages in various ways such as over costing, overpricing in local procurement and construction. This may be due to the general perception of the project staff that because foreign capital is involved, they should also enjoy some of extra benefit out of it. People think foreign aid meet the needs of government rather than their concerns (Devkota 1988)

\section{A Step Forward}

Traditionally, the people have mattered little of nothing to planners and administrators. In their scheme of themes, it is still quite common to consider them last of all, often as an afterthought. Government agencies in the capital often decide on programs for the people on their own, notifying their leaders later only in the case of their labor is needed for some construction activity. Control and authority, rather than support and equality has been used to formulate and implement the development project. And by their very nature, centralized government structure in Nepal is tending to keep local people out of the decision making processes. Some of the development activities are written on good papers and discussed at the Five Star Hotels in Kathmandu which is broadcasted by the national as well as international media. But at the same time local people do not know what is happening to their villages. Secondly, donor agencies regarded socio-cultural factors as of less concern to their work. The constraining influences of these factors led to many failures in reaching the poor. The poor live in societies which are highly stratified with castes and classes clearly demarcated in a rigid hierarchic order. Religion, language, ethnicity and other sociocultural forces divide the poor and undermine a unified challenge to the position of powerful elite groups.

Using knowledge of structural and sociocultural variables, it is important to formulate guidelines to emphasis on understanding the culture of the local group, introducing projects in terms of needs as the people perceive them, adapting traditions to new circumstances, respecting indigenous knowledge, and communicating development ideas in a language that the people understand. Development agencies also need strengthening in their use of sociocultural inputs 
needed for inducing participation. Without a change in the orientation of bureaucracies, the likelihood of sociocultural knowledge influencing development decisions remains remote. A major factor that contributes to success is to find out a comprehensive investigation of the life and culture of the target groups. It is also very important to consult local people for inputs to the project design and implementation. Sustainability without involvement of local people throughout the project activities is not achievable. Sustainability without social justice and empowerment of socially and economically disadvantaged groups in all aspects of life is impossible. And sustainable development would not be possible if we could not break the existing feudal social structure of Nepali society. To some of us such ideas may look too romantic. However, many ideas tend to appear romantic till they are put into action. To some people the idea of having a democratic system of governance could have appeared romantic during the Rana and Panchayat regimes. The quest for new possibilities both for society and for the social sciences should not be given up.

\section{Conclusion}

Development aid in general is expected to empower the socially and economically disadvantaged groups and lead to self-reliance but looking at commonly reported outcomes, it shows that often it leads to more powerlessness and dependency. Aid operated projects may help to curb short term human suffering but may be a factor in a long term for unfair distribution of benefits and even it may be a factor for future human suffering.

By examining the overall economic condition of the country in general, and Rapti-IRDP in particular, it can be stated that foreign aid has been unable to alleviate poverty and underdevelopment in Nepal. The practice and concept of IRDP strategy in Nepal has failed to improve the quality of rural poor. On the contrary, foreign aid has rather created dualism, widened the gulf between rural and urban population within region and created inequalities among regions. The gap between rich and poor has remained unchanged or even widened during this time (Baskota 1983; Khadka 1991; Devkota 1992; Mishra and Sharma 1983, Subedi 2001) Employment structure in most cases has remained more or less constant. The increasing or the constant trend of seasonal and permanent migration in Rolpa, Rukum and Salyan and Pyuthan districts shows that there has not been any particular relief in the state of employment or underemployment. In income trend as well no particular improvement was noticed when considered in terms of gross average household income. The trend of institutional services such as credit, fertilizer, improved seed, health and education have generally remained biased favoring the rich families and the accessible areas. In face of these situations, the performance of Rapti IRDP so far cannot be considered satisfactory. The conditions of the poor have always been highlighted for justification to get more aid. But once the project is actualized, the major share of the benefits goes to the international consultants and donor-expatriate patronage, national and local elites with the poor receiving only marginal shares. The Rapti - IRDP is a typical case to illustrate. This cycle has tended to repeat itself because it has successfully served the interest of the elite and bureaucracy. It also favored the creation of a vested interest group of elites and techno-bureaucrats and contributed to the continuation of the present system of government in Nepal. Using foreign aid and labor of the poor, the elite have been having a joy ride because they are the integral part of the decision-making system and have the resources to ensure its continuance. Willingly or unwillingly foreign aid has danced to their tones, and probably rightly so because even they would not really know what else to do! For many IRDP districts, the inflow of huge amounts of funds has killed the spirit of self-reliance, even in 
areas where people had traditionally depended on their own efforts and skills. We must look at why the development programs are not functioning properly in Nepal. There are problems in planning as well as implementation in the development system. In my opinion, it is the political system, the economic system and the bureaucratic system that fail to involve people. They do not allow opportunities for the poor people to make changes.

An important precondition to bring about change is a new approach of Aid agencies to work on partnership. The foreign aided projects should focus on strengthening the internal capability of generating resources, increasing investment in activities which complement the foreign aided projects in expanding the productive base of economy and ensuring effective utilization of aid.

Thus I argue that aid should attempt to help develop the resource base of the local population and capacity building. This requires a change in attitude among the donors from looking at the recipients as "passive recipients" to "active partners" who have immense indigenous knowledge and management practices. The more such conditions are created the more is the possibility of attaining sustainable development. The present attitude of thinking in terms of "I" should be transformed to "WE". The individualistic approach of present day should be changed in terms of collectivistic approach for tomorrow. Can one be convinced about this? Of course, it is an issue and, I realize, it has ideological and philosophical connotation, and our duty is understanding and changing this country by social, economic and political transformation. The development of Nepal is not possible without the structural transformation of Nepali society.

Note and Acknowledgements: This is a revised version of the earlier paper presented at Centre for Development Studies, University of Bergen, Norway in March 1999 where I was a student of Master of Philosophy in Social Anthropology. The theme of this paper was "Anthropology and Aid: Lessons from South". I am grateful to Prof. Dr. Kailash Nath Pyakuryal, and Dr. Om Gurung, Central Department of Sociology and Anthropology, Tribhuvan University for their comments and suggestions on earlier draft. I am alone responsible, however, for the views presented here.

\section{References Cited}

Adhikari, Shyam Prasad (2000). Rural Development in Nepal: Problems and Prospects (Second Edition). Lalitpur, Nepal. Sajha Prakashan.

APROSC (1980). Report on Rapti Baseline Survey (Main Text). Kathmandu. APROSC.

Baskota, Mahesh (1983). Foreign aid and the Poor: Some observations on Nepal's experience. In Foreign aid and development in Nepal: Proceeding of a seminar (Pp 35-78). Kathmandu: Integrated Development Systems.

Bista, Dor Bahadur (1991). Fatalism and Development: Nepal's Struggle for Development. Calcutta. Orient Longman Limited.

Bista, Santosh Kumar (2000). Rural Development in Nepal: An Alternative Strategy. Kathmandu, Nepal, Udaya Books.

Blaikie, Piers, John Cameron, and David Seddon (1980). Nepal in Crisis: Growth and Stagnation at the Periphery. Delhi, Oxford University Press.

Brown et al. (1987). Global Sustainability: Towards the definition. Environmental Management 11(6):713-719.

Chambers, Robert (1983). Rural Development: Putting the Last First. New York, Longman.

Chopra, Kanchan and Kadekodi, Gopal K. (1999). Operationalizing Sustainable Development: Economic-Ecological Modeling for Development Countries. Indo-Dutch Studies on

Development Alternatives 22. New Delhi, Sage Publication 
Devkota, Padam Lal (1992). Reflections on Participatory Developemnt in Rural Nepal. Nepal

Health Development Project, Tribhuvan University and University of Calgary.

Dhungana, Bhavani (1981). Foreign Aid: A free Lunch for Nepal. The Journal of Development and Administrative Studies, Vol. 3, No. 1 \& 2 (Pp 130-143). CEDA, Tribhuvan University.

Goldman, Abe (1995). "Threats to sustainability in African Agriculture: Searching for Appropriate Paradigm". In Human Ecology: An Interdisciplinary Journal. Volume 23 No. 3. New York, Plenum Press.

Haaland, Gunnar (1990). "Aid and Sustainable Development in a Dual Economy". In Forum for utviklingsstudier. No. 1

Hering, Peter (1997). "Forward". In Krishna B. Bhattachan and Chaitanya Mishra (Eds.) Developmental Practices in Nepal. Central Department of Sociology and Anthropology, Tribhuvan University, Kathmandu, Nepal.

Justice, Judith (1986). Policies, Plans and People: Foreign Aid and Health Development. Berkeley, University of California Press.

Karan, P.P. and Iijima, Shigeru (1986). "Environmental Protection and Economic Development in Nepal". In S. C. Joshi et al. (Eds.) Nepal Himalayas: Geo-Ecological Perspectives. India, Himalayan Research Group.

Khadka, Narayan (1991). Foreign Aid, Poverty and Stagnation in Nepal. New Delhi, Vikas Publishing House.

Luhan, Michael J. (1987). Too Much Aid, Too little Development: Nepal's Donor Dilemma. Development International, Denmark.

Mishra, Chaitanya (2000). Nepal: Five Years Following the Social Summit. Contributions to Nepalies Studies, Vol. 27, No. 1 (January 2000), 1-22.

Mishra, Chaitanya and Sharma, Pitamber (1983). Foreign Aid and Social Structure: Notes on Intra-State Relationships (1-17). In Foreign Aid and Development in Nepal. Proceeding of a Seminar (October 4-5). Kathmandu, Integrated Development Systems.
NESAC (1998). Nepal Human Development Report. Kathmandu, Nepal South Asia Centre.

Pandey, Devendra Raj (1983). "Foreign Aid in Nepal's Development: An Overview (270-312)." In Foreign Aid and Development in Nepal. Proceeding of a Seminar (October 4-5). Kathmandu, Integrated Development Systems.

Poudyal, Sriram (1982). Foreign Aid in Nepal. An analysis of Structure, Motive and Impact. The Journal of Development and Administrative Studies, Vol. 4, No. 1 \& 2 (Pp 179-214). CEDA, Tribhuvan University.

Pradhan, Bharat Bahadur (1982). Rural Development in Nepal: Problems and Prospects. Maharajgunj, Kathmandu, Nepal.

Singh, Katar (1999). Rural Development: Principles, Policies and Management (Second Edition). New Delhi, Vistaar Publications.

Stiller, Ludwig and Yadav, Ram Prakash (1979). Planning for People: A Study of Nepal's Planning Experience. Kathmandu, Sahayogi Prakashan.

Subedi, Madhusudan Sharma (2001). Development and Underdevelopment of Modern Health Services in Nepal (217-24). Kathmandu, Deva Vani, Vol. 4, No. 4.

UNDP (2000). Human Development Report 1999. New York UNDP. 